\title{
Rapid Divergence of Predator Functional Traits Affects Prey Composition in Aquatic Communities
}

\author{
Dominik W. Schmid, ${ }^{1, \star, \dagger}$ Matthew D. McGee, ${ }^{2, \ddagger}$ Rebecca J. Best, ${ }^{1, \$}$ Ole Seehausen, ${ }^{2,3}$ \\ and Blake Matthews ${ }^{1, *}$
}

1. Department of Aquatic Ecology, Center for Ecology, Evolution, and Biogeochemistry, Swiss Federal Institute of Aquatic Science and Technology (Eawag), Kastanienbaum, Switzerland; 2. Department of Fish Ecology and Evolution, Center for Ecology, Evolution, and Biogeochemistry, Eawag, Kastanienbaum, Switzerland; 3. Division of Aquatic Ecology and Macroevolution, Institute of Ecology and Evolution, University of Bern, Bern, Switzerland

Submitted November 6, 2017; Accepted October 30, 2018; Electronically published January 23, 2019

Online enhancements: appendix. Dryad data: https://dx.doi.org/10.5061/dryad.8rk23t4.

ABSTRACT: Identifying traits that underlie variation in individual performance of consumers (i.e., trait utility) can help reveal the ecological causes of population divergence and the subsequent consequences for species interactions and community structure. Here, we document a case of rapid divergence (over the past 100 generations, or $\sim 150$ years) in foraging traits and feeding efficiency between a lake and stream population pair of threespine stickleback. Building on predictions from functional trait models of fish feeding, we analyzed foraging experiments with a Bayesian path analysis and elucidated the traits explaining variation in foraging performance and the species composition of ingested prey. Despite extensive previous research on the divergence of foraging traits among populations and ecotypes of stickleback, our results provide novel experimental evidence of trait utility for jaw protrusion, gill raker length, and gill raker spacing when foraging on a natural zooplankton assemblage. Furthermore, we discuss how these traits might contribute to the differential effects of lake and stream stickleback on their prey communities, observed in both laboratory and mesocosm conditions. More generally, our results illustrate how the rapid divergence of functional foraging traits of consumers can impact the biomass, species composition, and trophic structure of prey communities.

\footnotetext{
* Corresponding authors; email: d.w.schmid@qmul.ac.uk, blake.matthews@ eawag.ch.

${ }^{\dagger}$ Present address: School of Biological and Chemical Sciences, Queen Mary University of London, London, United Kingdom; and Department of Evolutionary Ecology, Max Planck Institute for Evolutionary Biology, Plön, Germany.

* Present address: School of Biological Sciences, Monash University, Melbourne, Victoria, Australia.

$\S$ Present address: School of Earth Sciences and Environmental Sustainability, Northern Arizona University, Flagstaff, Arizona.

ORCIDs: Schmid, http://orcid.org/0000-0001-8908-3882; Best, http://orcid .org/0000-0003-2103-064X; Seehausen, http://orcid.org/0000-0001-6598-1434 Matthews, http://orcid.org/0000-0001-9089-704X.
}

Am. Nat. 2019. Vol. 193, pp. 000-000. (C) 2019 by The University of Chicago. 0003-0147/2019/19303-58062\$15.00. All rights reserved.

DOI: $10.1086 / 701784$
Keywords: trait utility, jaw protrusion, foraging performance, prey preference, rapid population divergence, Gasterosteus aculeatus.

\section{Introduction}

Adaptive divergence of consumer populations often involves the rapid evolution of multiple foraging traits, which can underlie both individual performance of consumers and the effect of consumers on their prey communities (Matthews et al. 2011; Schoener 2011; Thompson 2013). There is growing evidence that contemporary phenotypic evolution can affect not only population dynamics (Kokko and López-Sepulcre 2007; Smallegange and Coulson 2013) and interactions among pairs of species (Becks et al. 2010; Hiltunen and Becks 2014) but also the composition and structure of species-rich communities (Harmon et al. 2009; Weber et al. 2017; terHorst et al. 2018). Because of these wide-reaching effects, a sound understanding of the traits underlying variation in individual performance - trait utility - is critical for understanding the interaction between evolving organisms and their environments (Schluter 2000; Thompson 2013).

The complex relationships among multiple traits, individual performance, and environmental context often make it difficult to establish the links between trait evolution and the trait-mediated impacts of organisms on ecosystems. Evidence for trait utility is typically obtained from phenotype by environment correlations (Schluter 2000), functional trait models (Wainwright and Richard 1995), and experimental manipulation of trait variation (Wainwright and Shaw 1999). However, even for well-studied organisms, it is often challenging to identify the heritable traits responsible for effects on individual performance and subsequently for effects on prey communities and ecosystem dynamics (Matthews et al. 2011). 
The threespine stickleback (Gasterosteus aculeatus) is a particularly useful starting point for integrative analyses of the community consequences of consumer trait evolution. Previous work with stickleback has studied trait utility for a limited set of traits, including body size (Schluter 1993), gill raker characteristics (Robinson 2000), and jaw kinematics (McGee et al. 2013; Higham et al. 2017) as well as the heritability (Schluter et al. 2004; Berner et al. 2010, 2011) and plasticity (Day et al. 1994; Wund et al. 2012; Laskowski and Bell 2013; Lucek et al. 2014b) of these traits in a variety of environmental contexts. A separate body of work has also investigated the ecosystem effects of closely related stickleback species (Harmon et al. 2009; Des Roches et al. 2013), lineages (Best et al. 2017), and ecotypes (Matthews et al. 2016; Brunner et al. 2017). Yet there remains a critical gap between the two approaches. Whereas organism-focused studies of trait utility work to mechanistically link morphology with the capture of specific prey items (McGee et al. 2013; Higham et al. 2017), ecosystemfocused studies test for impacts of consumer trait distributions on whole seminatural communities in mesocosm experiments (e.g., Harmon et al. 2009). A missing link between these two approaches is a solid understanding of variation, over time and space, in the community context of trait utility-more specifically, how natural variation in prey communities can influence the trait evolution of consumers and how this, in turn, may shape prey communities and feed back to affect consumer trait evolution (Holt 1995; Schoener 2011; Hendry 2016; Matthews et al. 2016).

Here, we investigate how an unusually rapid case of adaptive population divergence, occurring over the past 150 years between a lake and a stream population of threespine stickleback (Marques et al. 2016), has led to divergence in several foraging traits - traits that could mediate both individual feeding performance and community-wide effects on prey species. Trait divergence between pairs of lake and stream stickleback populations is both widespread and common, although the nature and extent of divergence varies among population pairs, likely due to the environmental contrasts between lakes and streams and the influence of both adaptive and nonadaptive processes (Raeymaekers et al. 2017; Stuart et al. 2017). Foraging trait divergence between pairs is often characterized by lake populations having more and longer gill rakers than stream populations (Kaeuffer et al. 2011; Lucek et al. 2013; Stuart et al. 2017). This might reflect adaptations to foraging in open-water habitats (where zooplankton are more prevalent), compared with feeding on larger invertebrates and insects in streams (Kaeuffer et al. 2011; Lucek et al. 2012). However, there is a lack of experimental evidence for the utility of these and other functional foraging traits, and this limits our ability to make inferences about the underlying ecological drivers of natural selection. Gill rakers can aid planktivorous fish retain prey during selective filter feeding (Zaret 1980) and are often divergent in their structure (e.g., number, length, spacing) between limnetic and benthic ecotypes of postglacial freshwater fish (e.g., rainbow trout [Budy et al. 2005], white fish [Roesch et al. 2013], alewives [Post et al. 2008], stickleback [Bentzen and McPhail 1984; Schluter 1996]). However, in addition to gill rakers, foraging traits involved in prey pursuit and capture rather than retention can also affect foraging efficiency of planktivorous fish (Holzman et al. 2011; Higham et al. 2017). Jaw protrusion, for instance, influences the striking distance and directional suction potential of predator attacks (Wainwright et al. 2007; Holzman et al. 2008; Holzman and Wainwright 2009), while displacement advantage (the ratio of output to input displacement) constrains the opening velocity of the lower jaw (Barel 1983; Westneat 1994). Collectively, these traits might underlie not only individual performance and feeding efficiency (reducing prey biomass) but also prey selection (altering prey community composition and size structure). Furthermore, the prey species of plankton communities vary widely in their vulnerability to predation, with the more evasive species being more predatory (e.g., cyclopoid copepods) than the less evasive species (e.g., many herbivorous cladocerans). As a result, rapid evolution of stickleback foraging traits that govern feeding efficiency and preference (i.e., between copepods and cladocerans) could play a role in shaping both the species composition and the trophic structure of prey communities.

In this study, we combine detailed individual morphology with foraging experiments using a natural lacustrine zooplankton community as prey for stickleback. We chose stickleback individuals from a recently diverged pair of lake and stream ecotypes, which we raised under common laboratory conditions. Our results reveal novel evidence for the utility of jaw protrusion and gill rakers (width and length) - heritable foraging traits associated with the capture of zooplankton prey by stickleback. We further show that several foraging traits are divergent in this lakestream pair and investigate the link between these traits and the differential foraging efficiency and diet composition of stickleback when feeding on a natural zooplankton assemblage. To establish the link from foraging traits through performance to environmental impacts, we then compare the biomass reduction of different zooplankton prey species from our laboratory foraging experiments with changes in biomass of the same species in a previous mesocosm experiment using the same lake and stream ecotypes (Matthews et al. 2016). Overall, we illustrate how diverging multivariate phenotypes interact with the natural variability in prey community composition to determine both differential performance and community-wide effects of these lake and stream ecotypes. 


\section{Material and Methods \\ Sample Collection}

Parental threespine stickleback (Gasterosteus aculeatus) ecotypes were caught from the southeastern shores of Lake Constance (lake ecotype; $47^{\circ} 29^{\prime} 55^{\prime \prime} \mathrm{N}, 9^{\circ} 33^{\prime} 25^{\prime \prime} \mathrm{E}$ ) and several kilometers upstream at Aubach in Oberriet (stream ecotype; $47^{\circ} 19^{\prime} 38^{\prime \prime} \mathrm{N}, 9^{\circ} 34^{\prime} 24^{\prime \prime} \mathrm{E}$ ) in both 2013 and 2014 (fig. 1A). From these parents we bred cohorts of lake (2013: three families; 2014: 30 families) and stream (2013: five families; 2014: four families) fish. All juveniles were reared on Artemia and zooplankton for the first 2 months and later fed bloodworms (Chironomidae spp. larvae) daily and live zooplankton biweekly. These fish were adults $(\sim 1$ and 2 years old) at the time of the foraging experiment in 2015. To compare morphology between these laboratory fish and wild stickleback, we also captured adult fish from the same populations in 2015. Fish collections, husbandry, and experimental procedures were according to fishing permits obtained from the canton of Saint Gallen and animal care permits obtained from the veterinary office of the canton of Lucerne.

\section{Experimental Procedure and Behavioral Measures}

For all foraging experiments we used a complete randomized block design of multiple trials, each with factorial combinations of age $(1+; 2+)$ and ecotype (lake; stream), replicated 22 times ( $N=88$ fish used for foraging trials). Within each trial we used a single sex where possible and tried to minimize size differences between individuals. Prior to each trial the fish were not fed for $24 \mathrm{~h}$. We initially placed the fish into 10 -L tanks $(20 \mathrm{~cm} \times 20 \mathrm{~cm} \times 30 \mathrm{~cm})$ behind a partition and allowed the fish to acclimate for $5 \mathrm{~min}$ (see fig. A1; figs. A1, A2 are available online). During this time, a sample of live zooplankton $(500 \mathrm{~mL})$, collected on the same day from Lake Lucerne, was added and allowed to disperse on the other side of the partition. An additional random 500-mL sample of zooplankton was preserved for quantification of initial composition. The zooplankton composition of Lake Lucerne is comparable to that of Lake Constance and includes a combination of both herbivorous (e.g., Daphnia longispina, Daphnia galeata [mean \pm SE: $0.69 \pm 0.01 \mathrm{~mm}$ ], Bosmina longirostris [mean \pm SE: $0.42 \pm 0.01 \mathrm{~mm}$ ]) and omnivorous (e.g., Eudiaptomus gracilis [mean \pm SE: $0.51 \pm$ $0.01 \mathrm{~mm}$ ], Cyclops vicinus [mean \pm SE: $0.54 \pm 0.01 \mathrm{~mm}$ ]) taxa. In this community context, the predatory zooplankton tend to be more evasive than the herbivores because they are copepods with superior escape responses (Yen et al. 2015).

For each trial, we started all replicates simultaneously by raising the partition in each of the four tanks and allowing the fish to feed freely for $8 \mathrm{~min}$. We video recorded each fish (GoPro Hero 3 Silver). Later, the playback of those videos and the software JWatcher 1.0 (http://www.jwatcher .ucla.edu/) was used to quantify the total number of strikes, the time spent between strikes (i.e., search time), and the time until the first strike (i.e., latency time). The researcher analyzing these videos (D. W. Schmid) was blind to the identity (ecotype) of each fish. At the end of each trial, stickleback were sacrificed with an overdose of MS-222. Both gut contents and the estimated initial zooplankton samples were inspected to quantify prey species composition, abundance, and size via a dissecting microscope (Leica; fig. A2). Using the zooplankton counts from the initial sample and the final gut, we computed an index of prey electivity (Vanderploeg and Scavia 1979): $E^{*}=\left(W_{i}-n^{-1}\right)\left(W_{i}-n^{-1}\right)^{-1}$, where $n$ is the number of different prey types available and $W_{i}=\left(r_{i} p_{i}^{-1}\right)\left(r_{i} p_{i}^{-1}\right)^{-1}$, with $r_{i}$ and $p_{i}$ indicating the number of prey type $i$ in the gut and initial environment, respectively. The index ranges from -1 to +1 , with more negative and more positive values reflecting lower or higher representation, respectively, of a prey species in the gut relative to its availability in the zooplankton assemblage. Last, foraging efficiency on single prey items was calculated as $\mathrm{FE}=$ total number of prey consumed/total number of strikes recorded, and foraging efficiency on biomass was calculated as $\mathrm{FE}_{\mathrm{Bio}}=$ total biomass consumed/total number of strikes recorded.

\section{Morphological Measures}

After dissection, all sacrificed fish and our wild-caught fish (an additional 41 stream and 47 lake stickleback) were stained, as outlined in McGee et al. (2013). Next, each stickleback was photographed three times: dorsally, laterally with closed mouth, and laterally with opened mouth (fig. 1B). From these pictures we used 14 landmarks to measure four component traits related to feeding (table 1; see table A1; tables A1-A4 are available online). In addition, the left pectoral fin was removed at the base, spread, and photographed. We used another six landmarks to quantify two component traits and one functional system related to swimming (table 1; see table A1). Finally, we extracted the pharyngeal apparatus, counted all of the gill rakers on the ventral and dorsal limb of the first arch (gill raker number), and measured the length of the second-most-dorsal gill raker on the ventral limb (gill raker length; Berner et al. 2008). Last, the gap between this raker and the next-most-ventral gill raker (gill raker spacing) was measured.

All linear and area component traits or measures were first log or square root transformed, respectively. Subsequently, we either size standardized these traits to account for variation in standard length between ecotypes and ages, as described previously (McGee et al. 2013), or incorporated both standard length and raw trait values in the analysis. All functional systems, except for fineness ratio, were calculated 


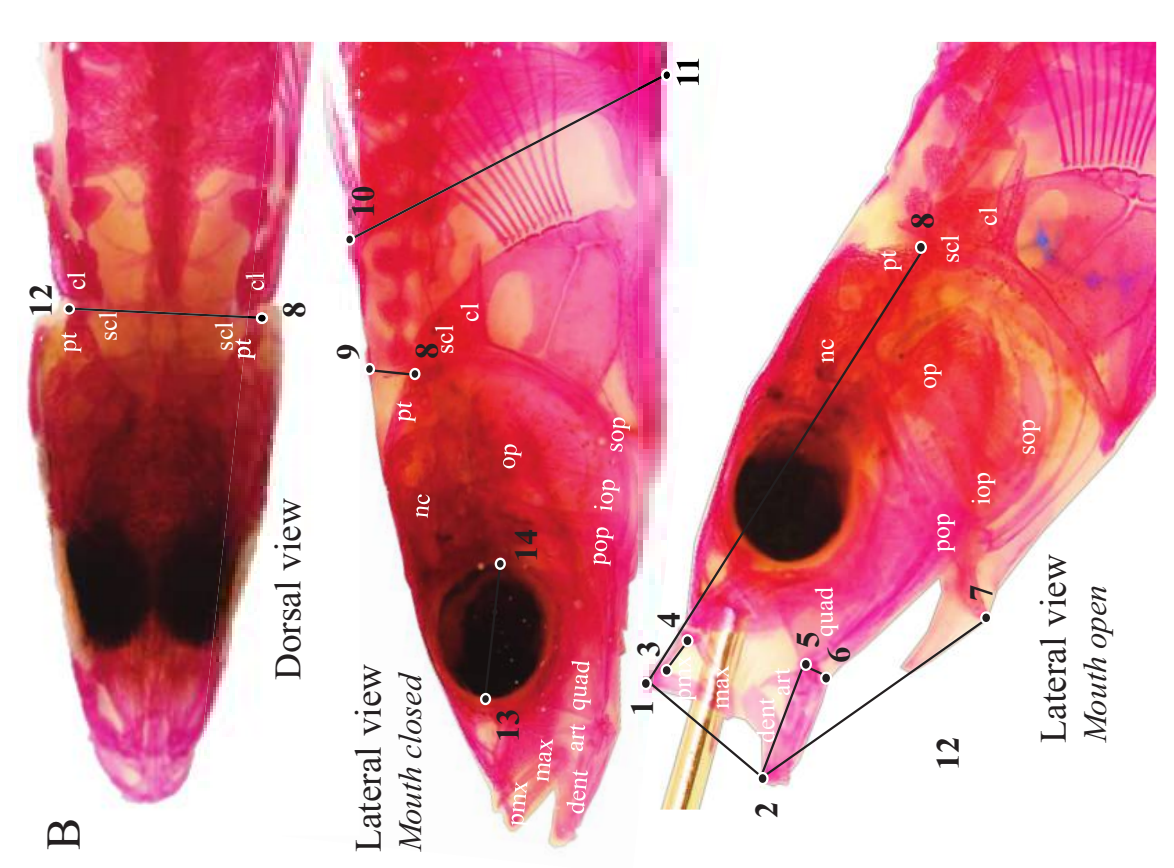

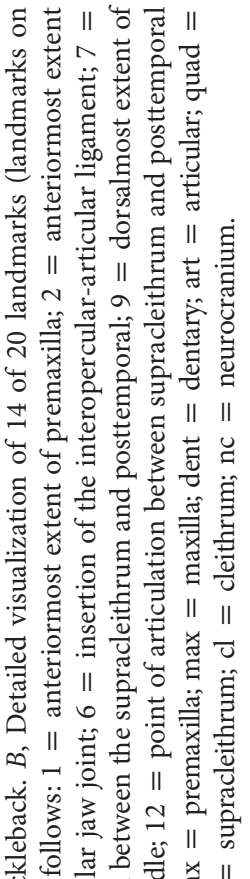

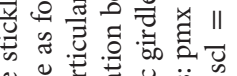

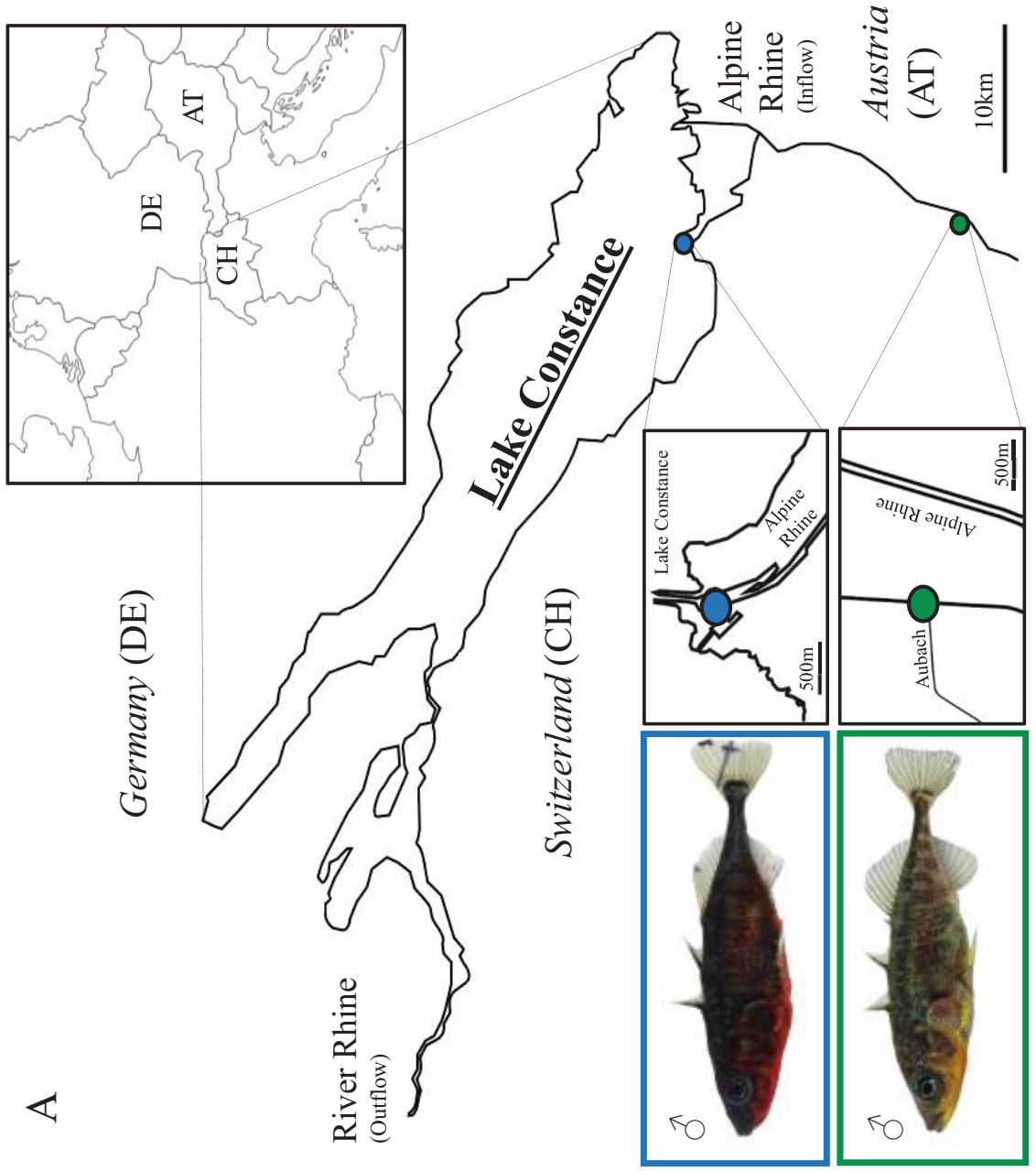

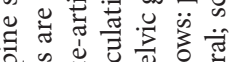

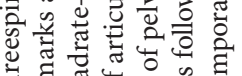

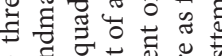

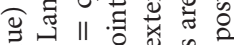

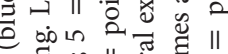

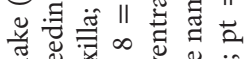

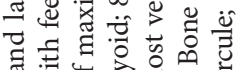
ส छ्ञ

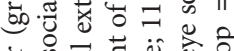

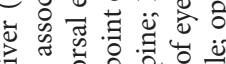
जै के के

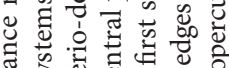

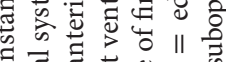
ठี సี兀 ० ह ह

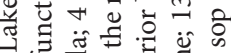

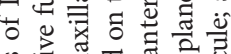

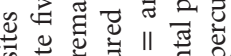

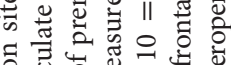

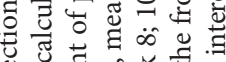

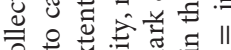

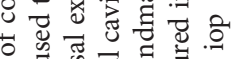

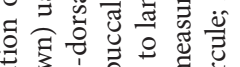

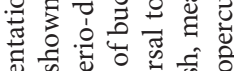
के

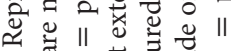

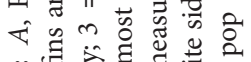

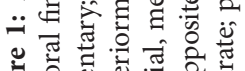

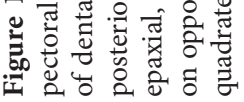




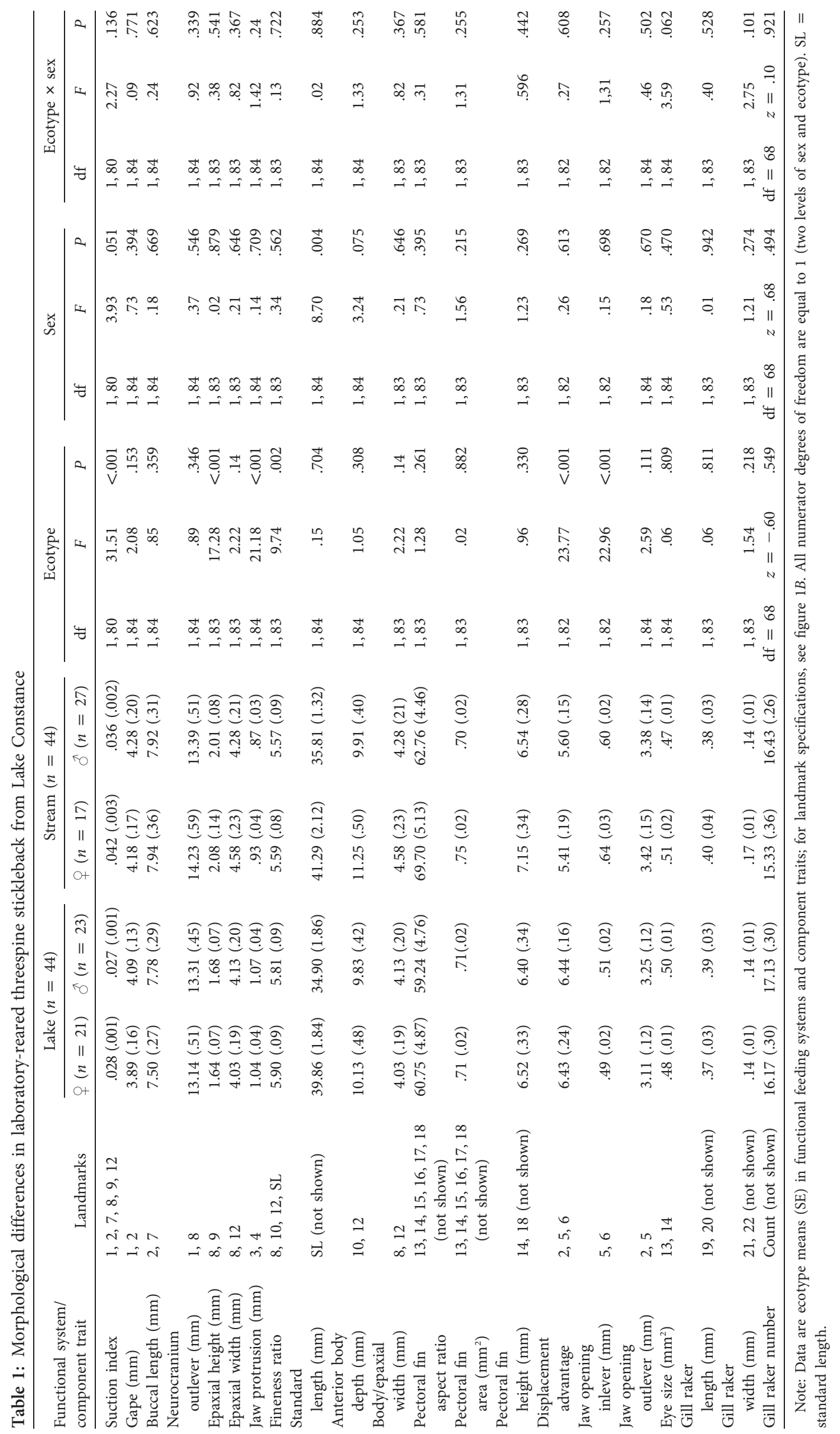

000

This content downloaded from 141.005.009.063 on February 11, 2019 02:49:50 AM 
from standardized data. The suction index model predicts suction potential within the buccal cavity empowered by force generation through the epaxialis and hence is the major determinant of overall suction performance in fish (Carroll et al. 2004; Wainwright et al. 2007). The index is calculated as SI $=\left(\mathrm{CSA}_{\text {Epax }} \times\left(L_{\text {in } /} L_{\text {out }}\right)\right) /($ Gape $\times$ Buccal Length $)$, a function of the amount of force generated through the epaxial muscle $\left(\mathrm{CSA}_{\mathrm{Epax}}\right)$, the moment arm of the epaxialis $\left(L_{\text {in }}\right)$ and neurocranial outlever $\left(L_{\text {out }}\right)$, and the projected area of the buccal cavity as a product of buccal length and gape (fig. $1 B$; table 1). The cross-sectional area of the epaxial muscle is the product of $\mathrm{CSA}_{\mathrm{Epax}}=\pi \times\left(E_{\mathrm{h}} \times\left(E_{\mathrm{w}} / 2\right)\right) / 2$, where $E_{\mathrm{w}}$ and $E_{\mathrm{h}}$ are the epaxial height and width, respectively. Displacement advantage - one of several traits that influences jaw opening velocity (Westneat 1994) —was computed as $\mathrm{DA}=\mathrm{Jaw}_{\text {outlever }} / \mathrm{Jaw}_{\text {inlever }}$, and pectoral fin aspect ratio was estimated as $A=h^{2} / S_{\text {total }}$, where $h$ and $S_{\text {total }}$ are pectoral fin leading edge and area, respectively (table 1; Wainwright et al. 2002). Jaw protrusion, eye and gape size, and gill raker length and width were always used as size-standardized measures (fig. $1 B$; table 1). Fineness ratio (i.e., a measure of streamlined body shape), $f=\mathrm{SL} /\left(\mathrm{ABD} \times E_{\mathrm{w}}^{0.5}\right)$, was the quotient of non-size-standardized data, with SL as standard length, $\mathrm{ABD}$ as anterior body depth, and $E_{\mathrm{w}}$ as epaxial width (fig. 1B; table 1; Walker 2004). Morphological differences between wild and laboratory fish may arise from dissimilarities in development or reproductive status (McGee and Wainwright 2013) or prey environment (e.g., through phenotypic plasticity; Lucek et al. 2014b). However, differences within laboratory fish reared under identical conditions more likely have a genetic origin (Marques et al. 2016).

\section{Ecotype Differences in Traits, Behavior, and Prey Selection}

We tested for effects of ecotype and sex on size-standardized traits using linear models (LMs) and a generalized linear model (GLM) for count data (e.g., gill raker number [Poisson distribution]). This was performed for both laboratory-reared and wild-caught fish. To test for differences in latency time, search time, strike frequency, total prey consumed, and foraging efficiency, we used linear mixed effects models with ecotype, sex, and age and their two-way interactions as fixed effects and trial as a random factor. A Friedman test was run to estimate differences in prey electivity $\left(E^{*}\right)$ between ecotypes within trials for each age class separately.

\section{Full-Experiment Bayesian Regression Model}

For a more comprehensive approach, we also fit a Bayesian path analysis to explain the total number of prey captured during each trial (i.e., a proxy of efficiency) based on ecotype, sex, and size; our suite of functional traits (jaw protrusion, eye area, gape, gill raker width, gill raker length, dis- placement advantage, suction index, pectoral fin aspect ratio, and fineness ratio); a behavioral trait (number of strikes); the total number of prey available to the fish; and a random effect of experimental trial. We repeated a similar model analysis where we split the total number of prey into two groups: evasive (copepod species) and nonevasive (cladoceran species) prey. Use of a single Bayesian model including all predictor and response variables (e.g., from ecotype through traits to performance) allowed us to compare the direct effects of ecotype, sex, and size with the effects of our suite of relevant foraging traits. In addition, the model allowed us to directly include both size (standard length) and raw trait values as predictors of feeding success, which is biologically more reasonable because capture success is determined by absolute trait values (e.g., gill raker size relative to prey size) rather than by residual values from size correction. The significance of effects in the model was based on whether $95 \%$ credible intervals of effect size (e.g., ecotype, size, or trait) overlapped with zero.

All analyses were performed using R (R Core Team 2016), and the data have been deposited in the Dryad Digital Repository: https://dx.doi.org/10.5061/dryad.8rk23t4 (Schmid et al. 2019). All model residuals were checked for normality and homoscedasticity; consequently, where necessary variables were transformed to meet model assumptions. Our regression analyses were performed in a Bayesian framework using STAN (Gelman et al. 2013). STAN is a Markov chain Monte Carlo (MCMC) sampler similar in spirit to BUGS and JAGS (Bürkner 2017 and references therein). However, STAN's MCMC sampler uses Hamiltonian MCMC in conjunction with a no U-turn sampler (NUTS); therefore, it is much more computationally efficient than typical Gibbs or Metropolis-Hastings algorithms and requires many fewer sampling iterations to achieve convergence. This improved computational efficiency makes it possible to run the type of "whole experiment model" described above. To set up the analysis, all continuous variables were transformed to have a mean of 0 and a standard deviation of 0.5 , with a normal prior of mean 0 and standard deviation 1 for both slope and intercept terms (Carpenter et al. 2017). All models were run for at least 10,000 MCMC iterations with four chains (equivalent to 1 million generations for a traditional MCMC sampler), and we verified that all four chains converged using the estimated potential scale reduction statistic Rhat (Carpenter et al. 2017).

\section{Results}

\section{Functional Traits}

Our (G)LM and path analysis approaches report broadly consistent effects of ecotype for several traits (fig. $2 A-2 E$ ). For example, fineness ratio, displacement advantage, and 

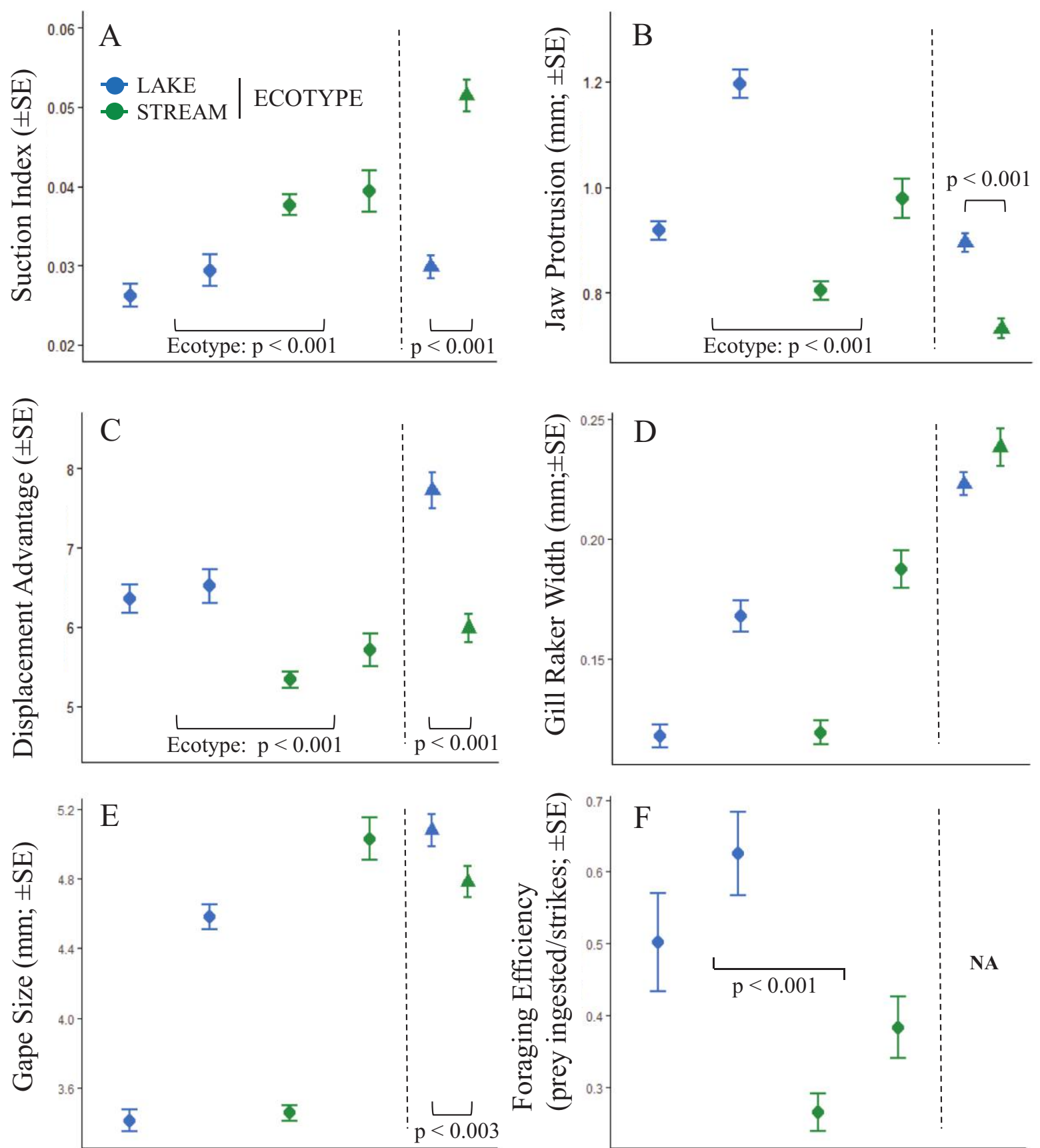

Age $1+$ Age $2+$ Age $1+$ Age $2+$ wild

Age 1+ Age 2+ Age 1+ Age 2+ wild
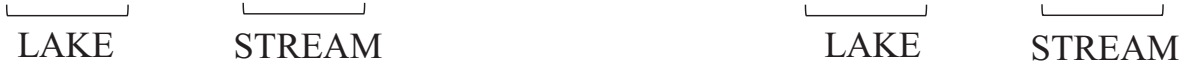

Figure 2: Ecotype differences in morphology and foraging efficiency. Average suction index $(A)$ was higher in stream than in lake fish; lake fish consistently projected their jaw farther $(B)$ and displayed a higher displacement advantage $(C)$ than stream fish; gill raker spacing $(D)$ and gape $(E)$ did not differ significantly between laboratory reared ecotypes; and foraging efficiency on pelagic prey by lake stickleback $(F)$ was twice as high as by stream ecotypes irrespective of age and sex $\left(F_{1,80}=20.82, P<.001\right)$. 
jaw protrusion were larger in lake fish (fig. 3, red lines originating from ecotype), whereas suction index was higher in stream fish ([G]LMs: table 1; Bayesian model: table 2, fig. 3, blue lines originating from ecotype). Neither approach revealed differences in eye size or gill raker traits (number, width, length) between ecotypes (table 2; fig. 3). Unlike the results from the LMs, the path analysis additionally revealed that laboratory-reared stream fish had a larger gape than lake fish (table 2; fig. 2E). As expected, in the path analysis size had strong effects on all traits except our ratio-based functional indices (e.g., displacement advantage; table 2). Trait divergence in wild fish was largely consistent with that in laboratory-reared fish, but the effects of sex in wild fish were more pronounced than those in laboratoryreared fish (table A3).

\section{Foraging Behavior and Efficiency}

All foraging-related behaviors differed consistently between ecotypes (table A2). Most notably, pelagic foraging efficiency, in terms of both captured number $\left(F_{1,82}=\right.$ 20.82, $P<.001)$ and biomass of prey per strike $\left(F_{1,81}=\right.$ $5.58, P=.021)$, was higher for lake fish than for stream fish regardless of age and sex (fig. $2 F$ ). On average, stream fish consumed more prey $\left(F_{1,61}=4.73, P=.033\right)$ but required more strikes to do so $\left(F_{1,61}=53.2, P<.001\right)$. Search time increased with age $\left(F_{1,61}=4.07, P=.048\right)$, and females showed a higher frequency of strikes than males $\left(F_{1,77}=\right.$ 5.99, $P=.017)$.

\section{Prey Selectivity and Trait-Mediated Community Change}

Prey from the family Bosminidae were the most abundant in the zooplankton mixture, followed by Daphniidae, Diaptomidae, and Cyclopidae (fig. A2). Yet lake stickleback, regardless of their age, preferentially captured more prey of the family Cyclopidae (indicated by a significantly positive selectivity index $\left[E^{*}\right]$; age $1: \chi^{2}=4.55, P=.033$; age 2 : $\left.\chi^{2}=18.18, P<.001\right)$ and either avoided or were unsuccessful at capturing prey from Bosminidae, Daphniidae, and Diaptomidae (indicated by $E^{*}$ ranging between -0.5 and 0.5; fig. A2; table A3). Stream stickleback showed no clear preference for either of the four prey types (fig. A2; table A3).

\section{Trait Utility}

Our path analysis to explain total prey capture success (fig. $3 A$ ) revealed positive effects of jaw protrusion and gill raker length and a negative effect of gill raker spacing (table 2). In contrast with our LMs, the path analysis showed that lake fish captured more prey overall than stream fish (fig. $3 A$, red line from ecotype to total prey) while making fewer strikes (fig. $3 A$, blue line from ecotype to strikes).
Whereas the latter result is consistent, the difference in overall prey consumption likely stems from differences based on sample means in comparison with estimated marginal means. Our path analysis incorporating prey evasiveness revealed that the capture success of evasive prey (i.e., copepods) increased with greater jaw protrusion and suction index and reduced gill raker spacing (fig. $3 B$; table A4). In this same analysis we found that capture success of nonevasive prey is positively related to gill raker length and pectoral fin aspect ratio. In addition to the indirect effects via functional and behavioral traits and consistent with the results from the prey electivity index, we found more evasive prey in the guts of lake fish and more nonevasive prey in the guts of stream fish (fig. 3B; table A4).

\section{Discussion}

Differentiation in foraging traits is common during adaptive population divergence in general (Schluter 2000; Grant and Grant 2002; Herrel et al. 2008) and during adaptive population divergence of stickleback in particular (Berner et al. 2009; Raeymaekers et al. 2017; Stuart et al. 2017). However, even for well-studied models of adaptive divergence, it remains a challenge to link divergence of specific components of multivariate phenotypes to the communityand ecosystem-wide effects of consumers. Here, we use a pair of lake and stream ecotypes of stickleback from Lake Constance with both phenotypic (Lucek et al. 2010, 2014a) and genomic (Marques et al. 2016) divergence that has evolved within only 100 generations. In this specific population pair, we report new evidence for morphological divergence in several important foraging traits and in feeding efficiency on zooplankton (fig. 2). We also establish a link between individual variation in key foraging traits, such as jaw protrusion and gill raker morphology, and feeding performance on a natural prey assemblage (fig. 3). Our path analyses help elucidate which foraging traits underlie the differential success in the capture of prey species with varying degrees of evasiveness (fig. 3B). Below, we elaborate on how the observed differences in traits and foraging efficiency between ecotypes might help explain the distinct ecological effects of this particular lake and stream population (Matthews et al. 2016; Brunner et al. 2017), illustrating how rapid trait evolution of consumers can have consequences for the biomass structure and species composition of prey communities (fig. 4).

\section{Rapid Morphological Differentiation of Lake and Stream Stickleback}

Previous work on functional trait models and kinematics identified several candidate traits that could play an important role in the capture of zooplankton by stickleback (McGee 


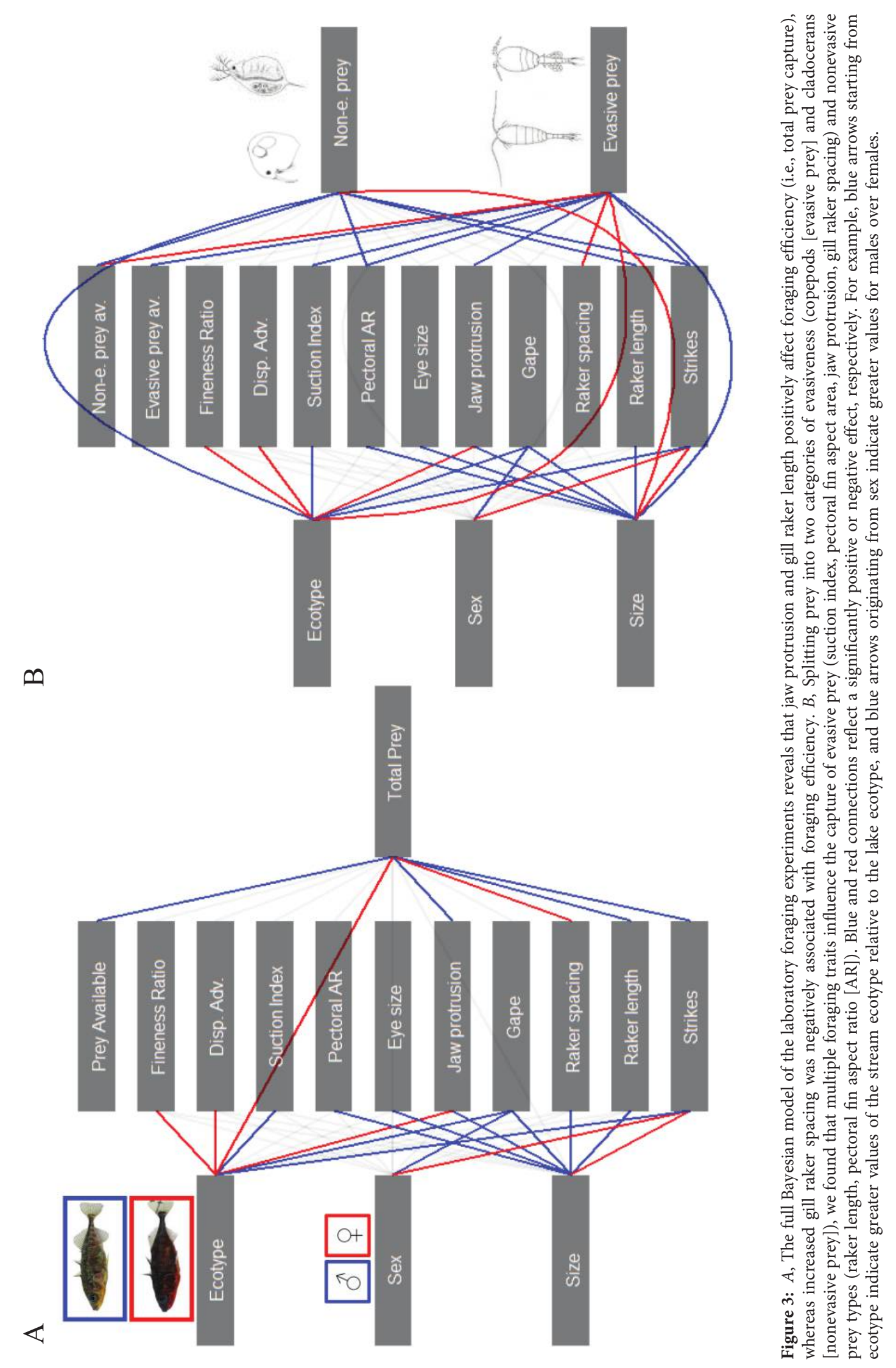

This content downloaded from 141.005.009.063 on February 11, 2019 02:49:50 AM 
Table 2: Assessing trait utility in relation to total prey captured via Bayesian path analysis

\begin{tabular}{|c|c|c|c|c|}
\hline Response & Explanatory & Estimate & Estimate error & $95 \% \mathrm{CI}$ \\
\hline Total prey consumed & Strikes & .02 & 0 & .01 to .02 \\
\hline Total prey consumed & Standard length & .43 & .24 & -.05 to .9 \\
\hline Total prey consumed & Sex $(M)$ & .01 & .07 & -.13 to .14 \\
\hline Total prey consumed & Ecotype (stream) & -.23 & .09 & -.4 to -.05 \\
\hline Total prey consumed & Gill raker length & .29 & .09 & .11 to .47 \\
\hline Total prey consumed & Gill raker width & -.32 & .11 & -.54 to -.11 \\
\hline Total prey consumed & Gape & -.12 & .17 & -.45 to .21 \\
\hline Total prey consumed & Jaw protrusion & .29 & .1 & .09 to .48 \\
\hline Total prey consumed & Eye area & -.34 & .18 & -.69 to .01 \\
\hline Total prey consumed & Pectoral fin aspect ratio & .1 & .1 & -.09 to .3 \\
\hline Total prey consumed & Suction index & .08 & .08 & -.07 to .23 \\
\hline Total prey consumed & Displacement advantage & .16 & .09 & -.02 to .34 \\
\hline Total prey consumed & Fineness ratio & -.09 & .08 & -.25 to .07 \\
\hline Total prey consumed & Total prey available & .01 & 0 & 0 to .01 \\
\hline Gill raker length & Standard length & .71 & .09 & .52 to .89 \\
\hline Gill raker length & Sex $(M)$ & .15 & .09 & -.03 to .33 \\
\hline Gill raker length & Ecotype (stream) & -.01 & .09 & -.18 to .16 \\
\hline Gill raker width & Standard length & .7 & .09 & .52 to .87 \\
\hline Gill raker width & Sex $(M)$ & .07 & .09 & -.1 to .24 \\
\hline Gill raker width & Ecotype (stream) & .12 & .08 & -.05 to .28 \\
\hline Gape & Standard length & .93 & .05 & .83 to 1.03 \\
\hline Gape & Sex $(M)$ & .21 & .05 & .11 to .31 \\
\hline Gape & Ecotype (stream) & .1 & .05 & .01 to .2 \\
\hline Jaw protrusion & Standard length & .68 & .08 & .52 to .84 \\
\hline Jaw protrusion & Sex $(M)$ & .06 & .08 & -.09 to .21 \\
\hline Jaw protrusion & Ecotype (stream) & -.44 & .08 & -.59 to -.29 \\
\hline Eye area & Standard length & .95 & .05 & .85 to 1.04 \\
\hline Eye area & $\operatorname{Sex}(M)$ & .07 & .05 & -.02 to .17 \\
\hline Eye area & Ecotype (stream) & -.04 & .04 & -.13 to .05 \\
\hline Pectoral fin aspect ratio & Standard length & .78 & .08 & .63 to .94 \\
\hline Pectoral fin aspect ratio & Sex $(M)$ & .02 & .08 & -.13 to .17 \\
\hline Pectoral fin aspect ratio & Ecotype (stream) & -.13 & .08 & -.27 to .02 \\
\hline Suction index & Standard length & .17 & .11 & -.04 to .38 \\
\hline Suction index & Sex $(M)$ & -.11 & .1 & -.32 to .09 \\
\hline Suction index & Ecotype (stream) & .42 & .1 & .22 to .61 \\
\hline Displacement advantage & Standard length & .17 & .11 & -.05 to .38 \\
\hline Displacement advantage & Sex $(M)$ & .08 & .11 & -.13 to .29 \\
\hline Displacement advantage & Ecotype (stream) & -.5 & .1 & -.69 to -.3 \\
\hline Fineness ratio & Standard length & .1 & .12 & -.13 to .33 \\
\hline Fineness ratio & Sex $(M)$ & -.01 & .11 & -.23 to .21 \\
\hline Fineness ratio & Ecotype (stream) & -.33 & .11 & -.55 to -.12 \\
\hline Strikes & Standard length & -.12 & .03 & -.18 to -.06 \\
\hline Strikes & $\operatorname{Sex}(M)$ & -.22 & .03 & -.27 to -.16 \\
\hline Strikes & Ecotype (stream) & .73 & .03 & .68 to .79 \\
\hline
\end{tabular}

Note: Shown is a full Bayesian path analysis on total prey in relation to all foraging traits, strike frequency, and total prey availability (using trial as a random effect) as well as ecotype, sex, size, and their effects on traits. The directionality of the effect size is given by sign. Effects for which the $95 \%$ credible interval (CI) does not overlap zero are significant.

et al. 2013). As predicted from this previous work, we found that lake ecotypes have greater jaw protrusion, greater opening jaw displacement advantage, and a more streamlined body shape, whereas stream stickleback have a higher suction force. For some traits these differences were larger in wild fish: wild stream stickleback exhibited larger suction potential than stream stickleback raised in the laboratory, and wild lake stickleback exhibited greater displacement advantage than laboratory-reared lake stickleback. It is possible that wild stream fish develop stronger epaxial muscles - the major determinant of suction force (Camp et al. 2015) — than fish reared in the laboratory on frozen chironomid larvae and 


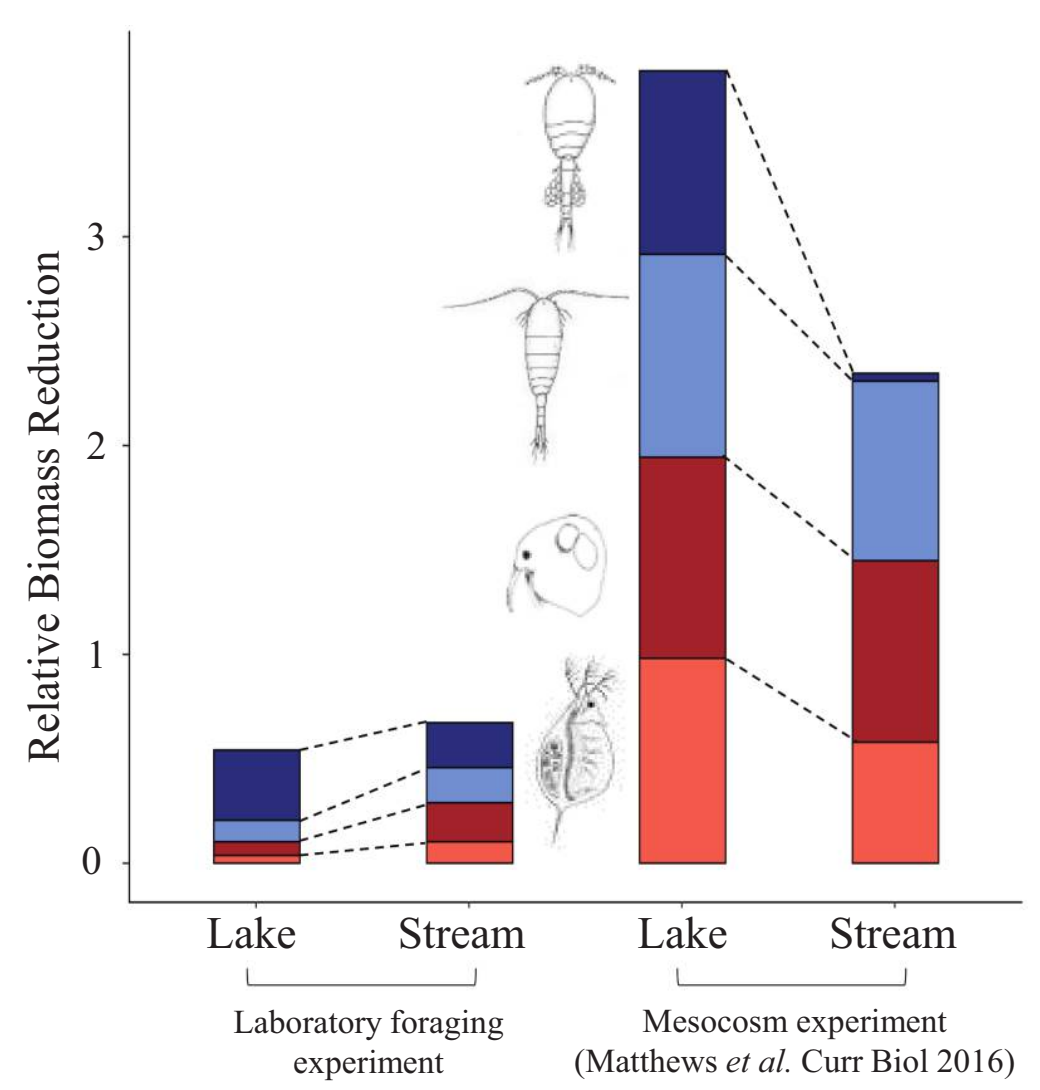

Figure 4: Biomass reduction relative to either the starting biomass in the foraging trials or the biomass in the mesocosms without stickleback (after 1 week). In both experiments, lake stickleback removed a proportionally higher amount of biomass of prey from upper trophic levels (i.e., Cyclopidae). The mesocosm experiment further highlights that in the long term lake stickleback have a higher impact on the zooplankton community than stream stickleback (Matthews et al. 2016). This may be because in the foraging trials they capture zooplankton more efficiently than stream fish, which had to strike much more often to capture a similar amount of prey in the short-term foraging experiment. Colors indicate taxa: orange $=$ Daphniidae; red $=$ Bosminidae; light blue $=$ Diaptomidae; dark blue $=$ Cyclopidae.

live zooplankton. Similarly, wild fish that regularly feed on live prey in open-water environments might develop a greater displacement advantage, in line with previous work on the morphological plasticity of body shape and jaw morphology (Lucek et al. 2014b). The wild fish were also at a more advanced reproductive stage than the laboratoryreared fish, and this could contribute to greater sexual dimorphism (McGee and Wainwright 2013).

Overall, the observed morphological differences between lake and stream ecotypes in our study (fig. 2) are broadly consistent with those from closely related teleost species occupying different habitats where distinct foraging environments drive divergence (Schluter 1996; Seehausen and Wagner 2014) and with those differences in foraging traits observed between other stickleback populations (McGee et al. 2013; Higham et al. 2017; Thompson et al. 2017). The lake-stream pair we studied has a notable lack of divergence in gill raker traits, which is uncommon for other instances of adaptive divergence between lake-stream populations (Kaeuffer et al. 2011; Stuart et al. 2017) and between ben- thic and limnetic species (Day et al. 1994). However, the pair we chose has a particularly rapid pace of divergence, likely resulting from a combination of divergent selection between lake and stream habitats as well as from the ongoing hybridization among multiple ancient lineages of stickleback that are present in the Lake Constance watershed (Lucek et al. 2010; Marques 2016; Best et al. 2017). This region of Switzerland is a zone of secondary contact between multiple lineages of stickleback that have different evolutionary histories of adaptation to freshwater environments (Lucek et al. 2012). The main population in Lake Constance is from an eastern Baltic lineage, but there is some evidence for adaptive introgression from western lineages that might have accelerated divergence between lake and stream genotypes (Lucek et al. 2012; Marques et al. 2016).

\section{Trait Utility in Stickleback}

Jaw protrusion was positively associated with capture success of zooplankton and evasive copepods. This supports 
the prediction that evolution of greater jaw protrusion is an adaptation for capturing zooplankton in general (Bellwood et al. 2015) and hints at its utility in capturing evasive zooplankton in particular (Holzman and Wainwright 2009; Yen et al. 2015). The utility of jaw protrusion is consistent with previous morphological work on a limneticbenthic stickleback species pair (from Paxton lake), which predicted but was unable to show empirically that greater jaw protrusion would increase the capture success of evasive zooplankton species (McGee et al. 2013). This is because jaw protrusion can rapidly place the strongest portion of the flow field next to the prey item before it has a chance to initiate an escape response. This is also consistent with our expectations from our particular lake-stream study system, where we have found that evasive copepods are a common prey item found in guts of wild lake fish (Lucek et al. 2012) and that lake fish cause stronger reductions of copepods in mesocosms over the short term (e.g., over 1-3 weeks) than stream fish (Matthews et al. 2016). More generally, our foraging trials provide the first experimental evidence for trait utility of jaw protrusion in a teleost fish-an essential step toward understanding both the causes and the consequences of adaptive phenotypic evolution of fish in general (Roesch et al. 2013) and of stickleback in particular (Schluter 1993; Holzman et al. 2008; Higham et al. 2017).

Our results also provide some experimental support for the oft-assumed utility of gill raker traits for zooplankton foraging efficiency (Zaret 1980). Specifically, we demonstrate that increased gill raker spacing reduces, while increased gill raker length improves, zooplankton capture success. Indeed, previous studies have outlined how these aspects of gill raker morphology form the mechanistic basis for how gill raker traits can improve the ingestion of small particles from the water column, specifically by redirecting the flow of particles into the esophagus (Sanderson et al. 2001). However, only one previous study of Coregonus whitefish (Roesch et al. 2013), which did not quantify gut contents after the feeding trials, addressed gill raker utility in relation to zooplankton capture success. Occupation of a zooplanktivorous niche is a common outcome among instances of postglacial freshwater fish divergence (Berner et al. 2010; Kaeuffer et al. 2011; Stuart et al. 2017). However, our results also illustrate greater complexity of this zooplanktivorous niche and suggest that the species composition and relative abundance of the prey community might influence adaptations to zooplanktivory. For example, our study provides novel evidence for the utility of gill raker length in the capture of nonevasive zooplankton (i.e., cladocerans) and both jaw protrusion and gill raker spacing for the capture of evasive zooplankton (i.e., copepods). Notably, such effects of rakers on prey capture was observed despite a lack of divergence in raker traits between ecotypes.
While our study reveals strong links between functional traits and feeding performance, we nevertheless observed direct effects of ecotype on total prey capture (higher for lake fish) and on both evasive (higher for lake fish) and nonevasive (higher for stream fish) prey capture, suggesting that unmeasured trait differences might explain additional variance (fig. 3). For example, it is likely that quantification of foraging kinematics could help explain variation in prey capture that remains unexplained by the traits we measured. Complex kinematic traits such as ram speed (Higham et al. 2017) and strike accuracy (Kane and Higham 2015), for instance, are highly likely to contribute to prey capture success, depending on the prey community context. In our analysis, the total number of strikes was a strong predictor of successful prey capture, but without high-speed video we could not link individual strikes with specific prey items so as to directly quantify performance on different prey items. Furthermore, it is likely that the basis of prey selection by stream and lake ecotypes is not simply a matter of functional traits and could also reflect unmeasured behavioral traits. In addition to measuring kinematic traits, we suggest that future work could examine, for example, whether behavioral feedbacks (e.g., positive feedback of learning) based on successful and unsuccessful strikes could help further explain individual variation in feeding performance on natural prey assemblages (Svanback and Bolnick 2007; Melián et al. 2014).

\section{Trait-Mediated Community-Wide Effects}

Our short-term foraging trials in the laboratory suggest that divergence in foraging traits and prey preference of predators can culminate in differential effects on prey communities, but how do such results scale up to larger and more natural ecosystems? To explore this, we quantified prey-specific biomass reduction from our foraging trials and from a previously published mesocosm study, which used the same fish populations and ecotypes (Matthews et al. 2016), and then compared how selectivity and trait-mediated performance can change zooplankton community composition and trophic structure. The lake ecotype reduced the relative biomass of cyclopoid copepods, the rarest prey (fig. A2), in both the laboratory setting and the mesocosm setting (foraging trial: 34\%; mesocosm experiment: $88 \%$ ), whereas the stream ecotype had weaker impacts (foraging trial: $21 \%$; mesocosm experiment: 4\%; fig. 4). Overall, lake fish exploited the pelagic prey community more effectively than stream fish in the mesocosm (Daphniidae: 98\%; Bosminidae: 97\%; Diaptomidae: 97\%; fig. 4; Matthews et al. 2016). Yet stream fish also strongly reduced the biomass of multiple species (Daphniidae: 57\%; Bosminidae: $88 \%$; Diaptomidae: $85 \%$; fig. 4). The difference in exploitation of cyclopoid copepods, however, is particularly striking. Cyclopoid copepods are voracious predators in the plankton community, have strong top-down 
effects on grazers of both the algal- and the microbial-based food chain (Fryer 1957; Matthews and Mazumder 2003), and, despite their evasiveness, may embody a highly profitable prey to target (Chepkwemoi et al. 2013). In connection with the link between jaw protrusion/gill raker morphology and capture success of copepod prey, the foraging trials and mesocosms experiments suggest that trait differences underlying performance (and potentially preference) of a top predator can alter the trophic structure of prey communities and may help explain some of the indirect effects of stickleback on ecosystem functioning (Harmon et al. 2009; Best et al. 2017).

Our results also provide new insights about the community context of trait divergence between lake and stream stickleback. In our particular study system, phenotypic differences between lake and stream fish have evolved rapidly over the past 150 years, potentially facilitated by introgression following secondary contact between two distant lineages (Lucek et al. 2010, 2012; Marques et al. 2016). The greater jaw protrusion of the lake stickleback might help explain why their diet in the natural lake environment is dominated by evasive copepods (Lucek et al. 2012). Although we find some evidence for trait utility of gill rakers, we did not find divergence in gill raker spacing and length between our lake and stream populations, even though such divergence is common in other lake-stream pairs (Kaeuffer et al. 2011; Lucek et al. 2013; Stuart et al. 2017). This might reflect differences among systems in (i) the time available for divergence, (ii) the strength and agents of divergent selection, and/or (iii) the genomic substrate for adaptation (i.e., given the presence of hybridizing lineages; Lucek et al. 2010). We also found that the stream fish had a greater suction index, which might explain why their natural diet in streams is dominated by prey associated with substrates (e.g., rocks, sediment, macrophytes), such as chironomid larvae, isopods, and ostracods (Lucek et al. 2012). When lake fish migrate into streams to breed, their diet rapidly converges to be more similar to the stream fish diet. However, more foraging experiments in benthic environments are necessary to identify those traits that are useful when foraging on benthic prey.

The present study links divergence in foraging traits of stickleback mechanistically with both individual performance in a community context (i.e., stickleback feeding on a natural zooplankton community) and the subsequent community-wide effects (i.e., of stickleback feeding on the zooplankton community). Our work highlights how rapid trait evolution of consumers can affect prey biomass and community structure and contributes to the growing body of evidence across multiple systems and taxa indicating that trait evolution can impact community and ecosystem dynamics (e.g., Grant and Grant 2002; Hiltunen and Becks 2014; Hendry 2016). While such research highlights the interplay between evolutionary and ecological dynamics (Schluter 2000; Matthews et al. 2011; Schoener 2011; McPeek
2017), we propose that more experimental tests of trait utility in different environmental contexts are necessary to improve our understanding of the community context of trait evolution (McPeek 2017; terHorst et al. 2018) and the mechanistic basis of feedbacks between trait and community change (Lion 2018; Patel et al. 2018).

\section{Acknowledgments}

We are grateful to D. Steiner for his technical support, D. Hohmann for her plankton identification expertise, J. Anaya-Rojas for his thoughts and statistical advice early on in the experiment, and D. A. Marques for the stickleback pictures shown in figure 1 . We are also thankful to the entire Eawag staff at Kastanienbaum for their support.

Statement of authorship: D.W.S., R.J.B., and B.M. conceived and designed the experiment; D.W.S. performed the foraging experiments; D.W.S. and M.D.M. performed the morphometric analysis; M.D.M., D.W.S., R.J.B., and B.M. analyzed the data; O.S. and B.M. provided laboratory facilities; and all authors contributed to the writing of the article.

\section{Literature Cited}

Barel, C. D. N. 1983. Towards a constructional morphology of cichlid fishes (Teleostei, Perciformes). Netherlands Journal of Zoology 33:357-424.

Becks, L., S. P. Ellner, L. E. Jones, and N. G. Hairston Jr. 2010. Reduction of adaptive genetic diversity radically alters eco-evolutionary community dynamics. Ecology Letters 13:989-997.

Bellwood, D. R., C. H. R. Goatley, O. Bellwood, D. J. Delbarre, and M. Friedman. 2015. The rise of jaw protrusion in spiny-rayed fishes closes the gap on elusive prey. Current Biology 25:2696-2700.

Bentzen, P., and J. D. McPhail. 1984. Ecology and evolution of sympatric sticklebacks (Gasterosteus): specialization for alternative trophic niches in the Enos Lake species pair. Canadian Journal of Zoology 62:2280-2286

Berner, D., D. C. Adams, A.-C. Grandchamp, and A. P. Hendry. 2008. Natural selection drives patterns of lake-stream divergence in stickleback foraging morphology. Journal of Evolutionary Biology 21:1653-1665.

Berner, D., A.-C. Grandchamp, and A. P. Hendry. 2009. Variable progress toward ecological speciation in parapatry: stickleback across eight lake-stream transitions. Evolution 63:1740-1753.

Berner, D., R. Kaeuffer, A.-C. Grandchamp, J. A. M. Raeymaekers, K. Räsänen, and A. P. Hendry. 2011. Quantitative genetic inheritance of morphological divergence in a lake-stream stickleback ecotype pair: implications for reproductive isolation. Iournal of Evolutionary Biology 24:1975-1983.

Berner, D., W. E. Stutz, and D. I. Bolnick. 2010. Foraging trait (co) variances in stickleback evolve deterministically and do not predict trajectories of adaptive diversification. Evolution 64:22652277.

Best, R. J., J. M. Anaya-Rojas, M. C. Leal, D. W. Schmid, O. Seehausen, and B. Matthews. 2017. Transgenerational selection driven by divergent ecological impacts of hybridizing lineages. Nature Ecology and Evolution 1:1757-1765. 
Brunner, F., J. Anaya-Roja, B. Matthews, and C. Eizaguirre. 2017. Experimental evidence that parasites drive eco-evolutionary feedbacks. Proceedings of the National Academy of Sciences of the USA 114:3678-3683.

Budy, P., T. Haddix, and R. Schneidervin. 2005. Zooplankton size selection relative to gill raker spacing in rainbow trout. Transactions of the American Fisheries Societv 134:1228-1235.

Bürkner, P.-C. 2017. brms: an R package for Bayesian multilevel models using Stan. Journal of Statistical Software 80:1-28.

Camp, A. L., T. J. Roberts, and E. L. Brainerd. 2015. Swimming muscles power suction feeding in largemouth bass. Proceedings of the National Academy of Sciences of the USA 112:8690-8695.

Carpenter, B., A. Gelman, M. D. Hoffman, D. Lee, B. Goodrich, M. Betancourt, M. A. Brubaker, et al. 2017. Stan: a probabilistic programming language. Journal of Statistical Software 76, doi:10.18637 /jss.v076.i01.

Carroll, A. M., P. C. Wainwright, S. H. Huskey, D. C. Collar, and R. G. Turingan. 2004. Morphology predicts suction feeding performance in centrarchid fishes. Journal of Experimental Biology 207:3873-3881.

Chepkwemoi, P., G. N. Bwanika, J. Kwetegyeka, G. Mbahizireki, L. Ndawula, and A. A. Izaara. 2013. Fatty acid profiles and growth of African catfish larvae fed on freshwater Cyclopoid copepods and Artemia as live starter feed. International Journal of Aquaculture 3:126-132.

Day, T., J. Pritchard, and D. Schluter. 1994. Ecology and genetics of phenotypic plasticity: a comparison of two sticklebacks. Evolution 48:1723-1734.

Des Roches, S., J. B. Shurin, D. Schluter, and L. J. Harmon. 2013. Ecological and evolutionary effects of stickleback on community structure. PLoS ONE 8:e59644.

Fryer, G. 1957. The food of some freshwater cyclopoid copepods and its ecological significance. Journal of Animal Ecology 26:263-286.

Gelman, A., J. B. Carlin, H. S. Stern, D. B. Dunson, A. Vehtari, and D. B. Rubin. 2013. Bayesian data analysis. 3rd ed. CRC, Boca Raton, FL.

Grant, P. R., and R. B. Grant. 2002. Unpredictable evolution in a 30 year study of Darwin's finches. Science 296:707-711.

Harmon, L. J., B. Matthews, S. Des Roches, J. M. Chase, J. B. Shurin, and D. Schluter. 2009. Evolutionary diversification in stickleback affects ecosystem functioning. Nature 458:1167-1170.

Hendry, A. P. 2016. Eco-evolutionary dynamics. Princeton University Press, Princeton, NJ.

Herrel, A., K. Huyghe, B. Vanhooydonck, T. Backeljau, K. Breugelmans, I. Grbac, R. Van Damme, and D. J. Irschick. 2008. Rapid large-scale evolutionary divergence in morphology and performance associated with exploitation of a different dietary resource. Proceedings of the National Academy of Sciences of the USA 105:4792-4795.

Higham, T. E., H. A. Jamniczky, K. Jagnandan, S. J. Smith, T. N. Barry, and S. M. Rogers. 2017. Comparative dynamics of suction feeding in marine and freshwater three-spined stickleback, Gasterosteus aculeatus: kinematics and geometric morphometrics. Biological Journal of the Linnean Society 122:400-410.

Hiltunen, T., and L. Becks. 2014. Consumer co-evolution as an important component of the eco-evolutionary feedback. Nature Communications 5:5226, doi:10.1038/ncomms6226.

Holt, D. B. 1995. How consumers consume: a typology of consumption practices. Journal of Consumer Research 22:1-16.

Holzman, R., D. C. Collar, R. S. Mehta, and P. C. Wainwright. 2011. Functional complexity can mitigate performance trade-offs. American Naturalist 177:E69-E83.
Holzman, R., S. W. Day, R. S. Mehta, and P. C. Wainwright. 2008 Jaw protrusion enhances forces exerted on prey by suction feeding fishes. Iournal of the Roval Society Interface 5:1445-1457.

Holzman, R., and P. C. Wainwright. 2009. How to surprise a copepod: strike kinematics reduce hydrodynamic disturbance and increase stealth of suction-feeding fish. Limnology and Oceanography 54:2201-2212.

Kaeuffer, R., C. L. Peichel, D. I. Bolnick, and A. P. Hendry. 2011. Parallel and nonparallel aspects of ecological, phenotypic, and genetic divergence across replicate population pairs of lake and stream stickleback. Evolution 66:402-418.

Kane, E. A., and T. E. Higham. 2015. Complex systems are more than the sum of their parts: using integration to understand performance, biomechanics, and diversity. Integrative and Comparative Biology 55:146-165.

Kokko, H., and A. López-Sepulcre. 2007. The ecogenetic link between demography and evolution: can we bridge the gap between theory and data? Ecology Letters 10:773-782.

Laskowski, K. L., and A. M. Bell. 2013. Competition avoidance drives individual differences in response to a changing food resource in sticklebacks. Ecology Letters 16:746-753.

Lion, S. 2018. Theoretical approaches in evolutionary ecology: environmental feedback as a unifying perspective. American Naturalist 191:21-44.

Lucek, K., D. Roy, E. Bezault, A. Sivasundar, and O. Seehausen. 2010. Hybridization between distant lineages increases adaptive variation during a biological invasion: stickleback in Switzerland. Molecular Ecology 19:3995-4011.

Lucek, K., A. Sivasundar, B. K. Kristjánsson, S. Skúlason, and O. Seehausen. 2014a. Quick divergence but slow convergence during ecotype formation in lake and stream stickleback pairs of variable age. Journal of Evolutionary Biology 27:1878-1892.

Lucek, K., A. Sivasundar, D. Roy, and O. Seehausen. 2013. Repeated and predictable patterns of ecotypic differentiation during a biological invasion: lake-stream divergence in parapatric Swiss stickleback. Journal of Evolutionary Biology 26:2691-2709.

Lucek, K., A. Sivasundar, and O. Seehausen. 2012. Evidence of adaptive evolutionary divergence during biological invasion. PLoS ONE 7:e49377.

$2014 b$. Disentangling the role of phenotypic plasticity and genetic divergence in contemporary ecotype formation during a biological invasion. Evolution 68:2619-2632.

Marques, D. A. 2016. Population genomics of adaptive radiation: a threespine stickleback perspective. PhD thesis. Universität Bern, Bern.

Marques, D. A., K. Lucek, J. I. Meier, S. Mwaiko, C. E. Wagner, L. Excoffier, and O. Seehausen. 2016. Genomics of rapid incipient speciation in sympatric threespine stickleback. PLoS Genetics 12:1-34.

Matthews, B., T. Aebischer, K. E. Sullam, B. Lundsgaard-Hansen, and O. Seehausen. 2016. Experimental evidence of an eco-evolutionary feedback during adaptive divergence. Current Biology 26:1-7.

Matthews, B., and A. Mazumder. 2003. Compositional and interlake variability of zooplankton affect baseline stable isotope signatures. Limnology and Oceanography 48:1977-1987.

Matthews, B., A. Narwani, S. Hausch, E. Nonaka, H. Peter, M Yamamichi, K. E. Sullam, et al. 2011. Toward an integration of evolutionary biology and ecosystem science. Ecology Letters 14:690-701.

McGee, M. D., D. Schluter, and P. C. Wainwright. 2013. Functional basis of ecological divergence in sympatric stickleback. BMC Evolutionary Biology 13:277. 
McGee, M. D., and P. C. Wainwright. 2013. Sexual dimorphism in the feeding mechanism of threespine stickleback. Iournal of Experimental Biology 216:835-840.

McPeek, M. A. 2017. The ecological dynamics of natural selection: traits and the coevolution of community structure. American Naturalist 189:E91-E117.

Melián, C. J., F. Baldó, B. Matthews, C. Vilas, E. González-Ortegón, P. Drake, and R. J. Williams. 2014. Individual trait variation and diversity in food webs. Advances in Ecological Research 50:207-241

Patel, S., M. H. Cortez, and S. J. Schreiber. 2018. Partitioning the effects of eco-evolutionary feedbacks on community stability. American Naturalist 191:381-394.

Post, D. M., E. P. Palkovacs, E. G. Schielke, S. I. Dodson, and S. I. Dodson. 2008. Intraspecific variation in a predator affects community structure and cascading trophic interactions. Ecology 89:20192032.

Raeymaekers, J. A. M., A. Chaturvedi, P. I. Hablützel, I. Verdonck, B. Hellemans, G. E. Maes, L. De Meester, and F. A. M. Volckaert. 2017. Adaptive and non-adaptive divergence in a common landscape. Nature Communications 8:267.

R Core Team. 2016. R: a language and environment for statistical computing. R Foundation for Statistical Computing, Vienna. http://www.R-project.org/.

Robinson, B. W. 2000. Trade offs in habiat-specific foraging efficiency and the nascent adaptive divergence of sticklebacks in lakes. Behaviour 137:865-888.

Roesch, C., B. Lundsgaard-Hansen, P. Vonlanthen, A. Taverna, and O. Seehausen. 2013. Experimental evidence for trait utility of gill raker number in adaptive radiation of a north temperate fish. Lournal of Evolutionary Biology 26:1578-1587.

Sanderson, S. L., A. Y. Cheer, J. S. Goodrich, J. D. Graziano, and W. T. Callan. 2001. Crossflow filtration in suspension-feeding fishes. Nature 412:439-441.

Schluter, D. 1993. Adaptive radiation in sticklebacks: size, shape, and habitat use efficiency. Ecology 74:699-709.

. 2000. The ecology of adaptive radiation. Oxford University Press, Oxford.

Schluter, D., E. A. Clifford, M. Nemethy, and J. S. McKinnon. 2004. Parallel evolution and inheritance of quantitative traits. American Naturalist 163:809-822.

Schluter, D., A. Rambaut, B. C. Clarke, and P. R. Grant. 1996. Ecological speciation in postglacial fishes. Philosophical Transactions of the Roval Society B 351:807-814.

Schmid, D. W., M. D. McGee, R. J. Best, O. Seehausen, and B. Matthews. 2019. Data from: Rapid divergence of predator functional traits affects prey composition in aquatic communities. American Naturalist, Dryad Digital Repository, https://dx.doi.org /10.5061/dryad.8rk23t4.

Schoener, T. W. 2011. The newest synthesis: understanding the interplay of evolutionary and ecological dynamics. Science 331:426-429.

Seehausen, O., and C. E. Wagner. 2014. Speciation in freshwater fishes. Annual Review of Ecology, Evolution, and Systematics 45:621-651.

Smallegange, I. M., and T. Coulson. 2013. Towards a general, populationlevel understanding of eco-evolutionary change. Trends in Ecology and Evolution 28:143-148.
Stuart, Y. E., T. Veen, J. N. Weber, D. Hanson, M. Ravinet, B. K. Lohman, C. J. Thompson, et al. 2017. Contrasting effects of environment and genetics generate a continuum of parallel evolution. Nature Ecology and Evolution 1:0158.

Svanback, R., and D. I. Bolnick. 2007. Intraspecific competition drives increased resource use diversity within a natural population. Proceedings of the Roval Societv B 274:839-844.

terHorst, C. P., P. C. Zee, K. D. Heath, T. E. Miller, A. I. Pastore, S. Patel, S. J. Schreiber, M. J. Wade, and M. R. Walsh. 2018. Evolution in a community context: trait responses to multiple species interactions. American Naturalist 191:368-380.

Thompson, C. J., N. I. Ahmed, T. Veen, C. L. Peichel, A. P. Hendry, D. I. Bolnick, and Y. E. Stuart. 2017. Many-to-one form-to-function mapping weakens parallel morphological evolution. Evolution 71:27382749.

Thompson, J. N. 2013. Relentless evolution. University of Chicago Press, Chicago.

Vanderploeg, H. A., and D. Scavia. 1979. Two electivity indices for feeding with special reference to zooplankton grazing. Lournal of Fishery Research Board Canada 36:362-365.

Wainwright, P. C., D. R. Bellwood, and M. W. Westneat. 2002. Ecomorphology of locomotion in labrid fishes. Environmental Biology of Fishes 65:47-62.

Wainwright, P., A. M. Carroll, D. C. Collar, S. W. Day, T. E. Higham, and R. A. Holzman. 2007. Suction feeding mechanics, performance, and diversity in fishes. Integrative and Comparative Biology 47:96-106.

Wainwright, P., and B. A. Richard. 1995. Predicting patterns of prey use from morphology of fishes. Environmental Biology of Fishes 44:97-113.

Wainwright, P., and S. Shaw. 1999. Morphological basis of kinematic diversity in feeding sunfishes. Journal of Experimental Biology 202:3101-3110.

Walker, J. A. 2004. Dynamics of pectoral fin rowing in a fish with an extreme rowing stroke: the threespine stickleback (Gasterosteus aculeatus). Journal of Experimental Biology 207:1925-1939.

Weber, M. G., C. E. Wagner, R. J. Best, L. J. Harmon, and B. Matthews. 2017. Evolution in a community context: on integrating ecological interactions and macroevolution. Trends in Ecology and Evolution 32:291-304.

Westneat, M. W. 1994. Transmission of force and velocity in the feeding mechanisms of labrid fishes (Teleostei, Perciformes). Zoomorphology 114:103-118.

Wund, M. A., S. Valena, S. Wood, and J. A. Baker. 2012. Ancestral plasticity and allometry in threespine stickleback fish reveal phenotypes associated with derived, freshwater ecotypes. Biological Journal of the Linnean Society London 105:573-583.

Yen, J., D. W. Murphy, L. Fan, and D. R. Webster. 2015. Sensorymotor systems of copepods involved in their escape from suction feeding. Integrative and Comparative Biology 55:121-133.

Zaret, T. M. 1980. Predation and freshwater communities. Yale University Press, New Haven, CT.

Associate Editor: David C. Collar Editor: Daniel I. Bolnick 